\title{
The Mechanical Behavior of Grouted Sleeve Splice Connections with and without Mechanical Interlocking Ring Under Axial Tensile Load
}

\author{
Abdallh M. Soliman, Hatem H. Ibrahim, Hossam A. Hodhod
}

\begin{abstract}
This research work thus presents rational procedure to design a grouted sleeve splice connection using a basic material such as standard pipes with little workmanship this provides the design with a good advantage in comparison to just using selection tables for costly proprietary similar connection. The mechanical behavior of such splices is a function of two important mechanisms: the bar-to-grout bond behavior and the sleeve-to-grout bond behavior. To accomplish the goal of this examination work, three arrangements with an all-out number of 66 grouted splice sleeve specimens were fabricated and tested under incremental axial tensile load. The specimens were preliminary designed according to the equations available in the literature to determine the initial sleeve dimensions. Different parameters have been examined, namely: grout compressive strength, bar embedded length, bar diameter, sleeve inner diameter, sleeve wall thickness and sleeve configuration. The examined parameters provide to have a significant impact on the mechanical behavior of the grouted splices. Considering the results, it was clear that steel bars with $18 \mathrm{~mm}, 25 \mathrm{~mm}$ and $32 \mathrm{~mm}$ diameter and $400 \mathrm{Mpa}$ yield stress can be adequately spliced and the tensile strength can be reached. The steel sleeve to the grouted splice sleeve connectors significantly improve the bar-to-grout bond strength through the confinement action added by the sleeve wall. Also welding interlocking steel rings can prevent the grout-to-sleeve bond Failure. Feasibility study for tested grouted sleeves reporting their adequacy in accordance with the code provisions of ACI 318-14[1] and ECP 203-2018[5] is presented. Moreover, design equations capturing the parameters affecting the bond strength, the confining pressure, and the required embedment length are derived.
\end{abstract}

Keywords: Precast concrete connection; Grouted splice; Mechanical Splice; Confinement; Bond Strength; bar embedment length.

Revised Manuscript Received on December 30, 2019.

* Correspondence Author

Abdallh M. Soliman*, lecturer Assistant, Structural Engineering Department, Faculty of Engineering, October High Institute, OHI, Giza, Egypt.

Hatem H. Ibrahim, Assistant Professor, Structural Engineering Department, Faculty of Engineering, Cairo University, Giza, Egypt. Email:

Hossma A. Hodhod, professor, structural Engineering Department, Faculty of Engineering, Cairo University, Giza, Egypt.

(C) The Authors. Published by Blue Eyes Intelligence Engineering and Sciences Publication (BEIESP). This is an open access article under the CC BY-NC-ND license (http://creativecommons.org/licenses/by-nc-nd/4.0/)

\section{INTRODUCTION}

Precast concrete construction, as a rule, of the requires connecting precast concrete components, such as columns, wall panels, and pier caps, to make the completed structure whether it may be a building or bridge. There are exceptionally few companies worldwide that can produce sleeve grouted splice pre- engineered and proprietary. The main idea of grouted splice sleeves depends on splicing two adjusted reinforcing steel bars by

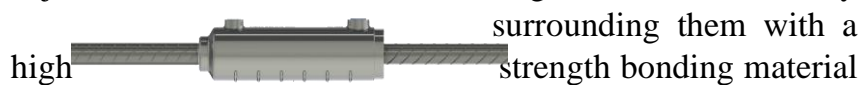
(grout) in a steel pipe as a mean of applying a confinement action to the grout to enhance the bond strength as shown in Fig.1.

Fig. 1 Precast concrete beam to beam connection on the left and column to column connection on the right with grouted splice sleeve connectors

\section{LITERATURE REVIEW}

The main objective of previous research was to examine the bond strength and the impact of the normal confinement pressure on the bar-to-grout bond strength of the grouted splice sleeve behavior and the ultimate tensile capacity of the splicing bars. The following section shows a review of the research work available within the writing, exploring the mechanical behavior of the sleeves in different loading and natural conditions. Darwin et. al. [4] concluded that the fourth root of the concrete strength gives an exact representation of the impact of concrete bond strength, and the yield strength of transverse reinforcement has no effect in deciding the development length. Einea et al. [6] tried a group of specimens of 6 grout-filled pipe splices. These specimens were provided with mechanical interlocking steel rings welded to the interior of the sleeve at $1 \mathrm{in}$. $(25.4 \mathrm{~mm})$ from its both ends. Theses specimens had a constant pipe diameter of 2 in., grout compressive strength of $6.5 \mathrm{ksi}$ and $10 \mathrm{ksi}$. For each grout compressive strength, 3 distinctive bar embedment lengths were utilized: 7 in., 6 in., and 5 within. The specimens were tested beneath axial tensile load to 


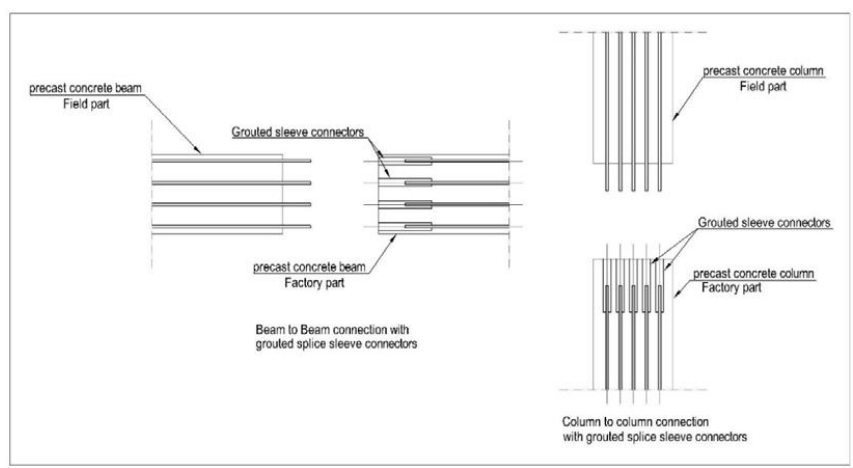

investigate the mechanical behavior of the grafts in terms of 2 diverse association parameters, specifically the grout compressive strength and the development length. It was concluded that utilizing welded steel rings inside the grouted splice pipe at both ends of the sleeve can increase the capacity of the splice by adding of including more confiment pressure to the spliced bar and improve the bond strength. Meanwhile, they derived equations (1)-(2) to evaluate the radial confinement pressure $f \mathrm{n}$ based on the measured tangential strain $\varepsilon s$ in the pipe after testing the grouted splice connector:

$$
\begin{aligned}
& \mathrm{Ts}=\varepsilon_{\mathrm{s}} \mathrm{t}(\Delta \mathrm{L}) \mathrm{E} \\
& f \mathrm{n}=\frac{2 T s}{d i(\Delta \mathrm{L})}=\frac{2 \varepsilon s \mathrm{t}(\Delta \mathrm{L}) \mathrm{E}}{d i(\Delta L)}=\frac{2 \varepsilon s \mathrm{t} \mathrm{E}}{d i}
\end{aligned}
$$

It ought to be noted that the previously mentioned equations have a determined parameter to discover out the confining pressure which is the measured tangential strain within the pipe. Unless the tangential strain of the pipe is measured, the confining pressure will not be calculated. Ling et al. [8] examined the mechanical behavior of two distinctive shapes of splice sleeve connectors: Welded bar sleeve (WBS) and Tapered head sleeve (THS). In WBS introducing specimens, they increased the confining action of the sleeve by implies of presenting welded bars to the interior of the sleeve lessening the grouting range. On the other hand, they developed the THS by decreasing the diameter of both ends of the sleeve itself as ways of interlocking the grout the sleeve to inhibit the grout sleeve-bond failure. The results showed that decrease of the sleeve diameter results in increasing the tensile capacity by means of improving the confinement stress on the surrounding grout. Equation (3) WBS and (4) the THS were based on a linear regression method to compute the bond strength as function of grout compressive strength, the bar diameter, and the interior diameter of the sleeve.

$$
\begin{aligned}
& \frac{U b}{\sqrt{f u . g}}=-6.7 * 10^{-3 *} \mathrm{~d}_{\mathrm{sl}}-6.896 * 10^{-3 *} \mathrm{~L}_{\mathrm{b}}+3.430 \\
& \frac{U b}{\sqrt{f u . g}}=-9.037 * 10^{-3 *} \mathrm{~d}_{\mathrm{sl}}-14.642 * 10^{-3 *} \mathrm{~L}_{\mathrm{b}}+4.958
\end{aligned}
$$

Where:

$\mathrm{Ub}=$ bond stress in sleeve under tensile load $(\mathrm{N} / \mathrm{mm} 2)$

fu.g = Grout compressive strength in sleeve $(\mathrm{N} / \mathrm{mm} 2)$

$\mathrm{dsl}=$ internal diameter of sleeve $(\mathrm{mm})$

$\mathrm{lb}=$ bar embedded length $(\mathrm{mm})$

Eliya and George [7] considered the specified development length of a grouted splice sleeve connector for two types of sleeves in this investigation: threaded sleeves ( $\mathrm{T}$ series) and threaded with end plates (P series). They expressed that the behavior of the splices depended on the confining stress which is considered the bond divided by the shear friction coefficient between the bar and the surrounding grout. A 3D finite element model for 2 specimens was displayed and appeared that the coefficient of friction ranged from 1.6 to 1.7 which is the same value obtained from the exploratory test data indicating the reliability of the conclusion . Additionally, the model showed that the value of $0.2 f$ c for the confinement stress is satisfactory to reduce the probability of crushing and excessive cracking for the grout surrounding the spliced bars. The following equations, referred to herein after as (5)-(8), derived by Eliya and George illustrate the relation between the required embedded length, $l b$, with an applied force, $P$, and different parameters affecting the behavior of the grouted splice sleeves such as the confinement stress, $F \mathrm{n}$, and the grout

$$
\mathrm{F}_{\mathrm{b}}=\mathrm{F}_{\mathrm{n}} \mu
$$
compressive

$$
\begin{aligned}
& \mathrm{F}_{\mathrm{n}} \mathrm{d}=2 \mathrm{t} \mathrm{F}_{\mathrm{s}} \\
& \mathrm{F}_{\mathrm{n}}=\frac{2 t F s}{d} \leq 0.2 \mathrm{fc} \\
& \mathrm{l}_{\mathrm{b}}=\frac{p}{\pi d b \mu \min \left(0.2 F c, \frac{2 t F s}{d}\right)}
\end{aligned}
$$

Where:

$\mathrm{Fb}=$ the bond strength between the bar and the surrounding grout

$\mu=$ the coefficient of friction between the bar and the grout

$d=$ the inside diameter of the sleeve

$t=$ the sleeve wall thickness

$F_{\mathrm{C}}=$ the specified yielding stress of the sleeve material

$d \mathrm{~b}=$ the bar diameter

$\mathrm{lb}=$ embedded length

Belal [3] tested 70 sleeve grout splice specimens with different parameters namely grout type, sleeve thickness, bar dimeter (12 and $16 \mathrm{~mm}$ ), embedded length, sleeve configuration and eccentricity effect. The researcher concluded that steel sleeve to the grouted splice sleeve connectors significantly improve the bar-to-grout bond strength through the confinement action added by the sleeve wall. Welding interlocking steel rings with $6 \mathrm{~mm}$ minimum thickness can prevent the grout-to-sleeve bond failure.

Belal [3] also derived design equations referred to herein after as (9)-(12). These present a simple formula using a linear regression method to evaluate the bar-grout bond strength of the grouted splices as a function of the initial bond strength, $\tau$ bi, the confinement stress Fn, and the confinement coefficient, $\mathrm{Bc}$. They can also determine which sleeve fits the spliced bars using available standard steel pipes and commercially available grouts to accommodate precast or cast-in-situ concrete construction. 


$$
\tau_{\mathrm{bt}}=\tau_{\mathrm{bi}}+\mu_{\mathrm{b}} * \mathrm{Fn}
$$

$$
\begin{aligned}
& \tau_{\mathrm{bi}}=0.75 \sqrt{\mathrm{Fg}} \\
& \mathrm{Fn}=\mathrm{Bc} * \mathrm{Fg}
\end{aligned}
$$

$$
\mathrm{Bc}=17.841 * \frac{1}{d s i}+0.015 * \mathrm{db}-0.0024 * \frac{t s * E s}{\pi *(\mathrm{ds} \mathrm{avg})^{2}}
$$

Where:

$\tau \mathrm{bt}=$ total bar - to- grout bond strength $(\mathrm{MPa})$

$\tau \mathrm{bi}=$ initial bar -to- grout bond strength $(\mathrm{MPa})$

$\mu b=$ coefficient of friction between the spliced bars and grout $=1.0$

$\mathrm{Fn}=$ confinement stress $(\mathrm{MPa})$

$\mathrm{Fg}=$ grout compressive strength $(\mathrm{MPa})$

$\mathrm{Bc}=$ confinement coefficient

$\mathrm{dsi}=$ inner diameter of sleeve $(\mathrm{mm})$

$\mathrm{db}=$ bar diameter $(\mathrm{mm})$

ts= sleeve wall thickness (mm)

$\mathrm{Es}=$ the modulus of elasticity of the sleeve material (MPa)

$\mathrm{ds}{ }_{\mathrm{avg}}=$ average diameter of the sleeve $(\mathrm{mm})$

\section{OBJECTIVE}

The main aim of this research is to present a rational procedure to design grouted sleeve splice connection using the commercial sleeve (steel pipe ASTM) [2] and commercial available grouts. This can be achieved by derivation of comprehensive new design equations that can be used to design sleeve grouted splice with or without steel rings considering all the parameters affecting the joint and achieve all the code requirements for splicing steel bars. Based on these equations, grouted sleeve specifications selection tables can be developed for different bar diameters.

\section{EXPERMENTAL PROGRAM}

The objective of testing the grouted splice sleeve specimens was to find out the effect of each of the interacting parameters such as grout compressive strength, sleeve diameter, sleeve wall thickness, sleeve configuration (installing steel rings or not), steel bar diameter and bar embedded length. Furthermore, the whole behavior of the splice under axial tensile loading is studied.

\section{A. DESCREPTION OF SPECIMENS}

Three series with a total number of 66 specimens of grouted splice sleeve connectors were prepared to be tested in the experimental study. Each series differs from the others in some parameters such as the grout compressive strength, the sleeve diameter, and the bar embedment length. All the specimens where made up of available commercial pipes and grouts. Table- I reports the available steel pipes conforming to ASTM A106 Grade B [2] and having a minimum yield strength of $240 \mathrm{MPa}$. Meanwhile, the commercially available grouts used in this research work were SIKAgrout ${ }^{\circledR} 200$ (G200) [9] and SIKAgrout ${ }^{\circledR} \quad 214$ (G214) [10]. The compressive strength of the grouts was measured at the age of 7 days to find out the developing of the grout strength till the testing day of the specimens. Also, it was measured on the testing day using standard $50 \times 50 \times 50 \mathrm{~mm}$ cubes.

Five types of proposed splice sleeve connectors were used. The entire sleeves were named according to the interacting parameters affecting the behavior of each sleeve. For example, specimen G200-D18-120-SL73-R stands for a grouted splice sleeve connector made from a Sleeve SL73 and filled with grout G200. The D18 symbol stands for the diameter of the spliced bars and $\mathrm{R}$ stands for specimens enhanced with interlocking steel rings. In addition, the number 120 in the middle name of the specimen presents the embedment length of the spliced bars. Specimens were named with a symbol of GS, GSS, and GSSR. GS symbol stands for the grout splice specimens with no sleeve which are used in determining the initial bond strength of the grouted splices as shown in Fig. 2. The specimens with GSS symbol are the grout splice sleeve specimens without interlocking steel rings which are used to determine total bond strength as sown in Fig. 3. Meanwhile, GSSR stands for the grout splice sleeve specimens with interlocking steel rings which are used to determine specimens total bond strength as shown in Fig.4.

appendix A Table - A1 lists the 66 specimens in terms of specimen's number, specimens ID, grout type, sleeve outer diameter (ds out), sleeve inner diameter (ds in), sleeve wall thickness (ts), sleeve length (Ls), bar diameter (db), and bar embedded length (Lb).
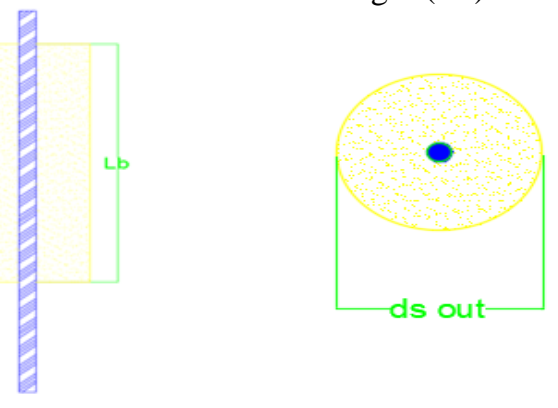

Fig. 2 Details of GS specimens for series 1 
The Mechanical Behavior of Grouted Sleeve Splice Connections with and without Mechanical Interlocking Ring Under Axial Tensile Load

Table- I: Properties of steel pipes (ASTM A106 Grade B, 2015), and 18 mm, 25 mm and 32 mm reinforcing steel bars.

\begin{tabular}{|c|c|c|c|c|c|c|c|}
\hline Item & $\begin{array}{c}\text { Nomin } \\
\text { al } \\
\text { diameter, } \\
\text { mm }\end{array}$ & Pipe ID & $\begin{array}{c}\text { Outside } \\
\text { diameter, } \\
\text { mm }\end{array}$ & $\begin{array}{c}\text { Inside } \\
\text { diameter, } \\
\text { mm }\end{array}$ & $\begin{array}{c}\text { Wall } \\
\text { thickness, } \\
\text { mm }\end{array}$ & $\begin{array}{c}\text { Cross section } \\
\text { area, mm2 }\end{array}$ & $\begin{array}{c}f_{\mathrm{y}} / f_{\mathrm{u}} \\
\text { (Nominal) } \\
, \mathrm{MPa}\end{array}$ \\
\hline \multirow{5}{*}{$\begin{array}{l}\text { Steel } \\
\text { Pipes }\end{array}$} & 63.5 & SL73 & 73.03 & 59.01 & 7.01 & 1454.51 & \multirow{5}{*}{$240 / 420$} \\
\hline & 76.2 & SL 88 & 88.9 & 73.66 & 7.62 & 1946.54 & \\
\hline & 76.2 & SL 88* & 88.9 & 77.92 & 5.49 & 1439.18 & \\
\hline & 88.9 & SL 101 & 101.6 & 90.12 & 5.74 & 1729.31 & \\
\hline & 101.6 & SL 114 & 114.3 & 97.18 & 8.56 & 2844.71 & \\
\hline \multirow{3}{*}{ Steel Bars } & - & D 18 & 18 & - & - & 254.57 & $400 / 600$ \\
\hline & - & D 25 & 25 & - & - & 491.07 & $400 / 600$ \\
\hline & - & D 32 & 32 & - & - & 803.57 & $400 / 600$ \\
\hline
\end{tabular}
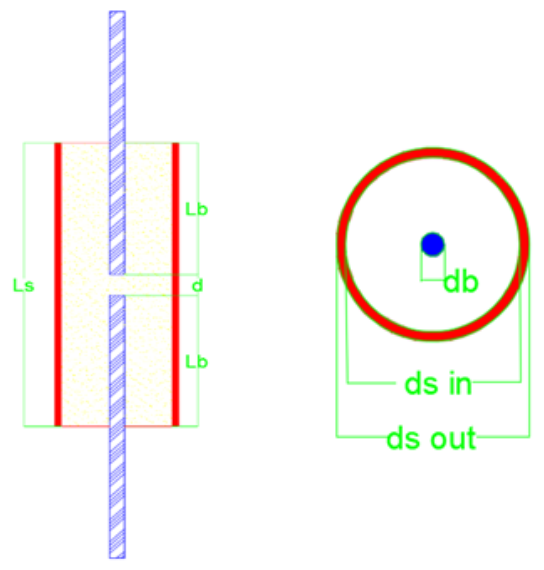

Fig. 3 Details of GSS Specimen for series 2

Fig 4

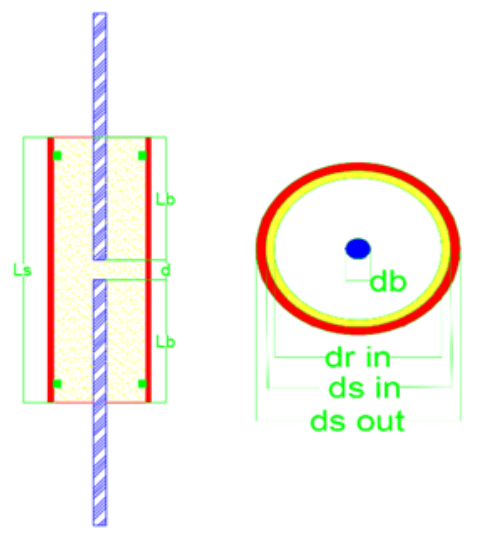

for series 3

\section{B. DESIGN OF SPECIMEN}

The proposed grouted splice sleeve connector is mainly a steel pipe filled with a high strength non-shrink grout to act as the bonding and force transferring material between the two spliced reinforcing bars through the sleeve wall. The force is transferred from one rebar to the grout through the bond action that is primarily developed by the indentations on the deformed bars interlocking with the grout. Then, the force is transmitted from the grout to the pipe by friction and the interlocking steel rings that resist the expectable movement of the grout out the pipe. The force is then transmitted from the pipe to the grout on the other half of the connector and eventually to the other spliced rebar.

Two design approaches were used to set a preliminary design for the proposed bar splice sleeve. The design procedures depend on the equations available in literature derived by Eliya and George [7], and Belal [3] to assess the sleeve dimensions and mechanical behavior which are affected by various interacting parameters such as the bar embedded length and the grout compressive strength. Different grout-to-sleeve interlocking techniques were used in literature such as welded reinforcing steel bars to the inside of the sleeve, tapered head sleeves to prevent the grout form slipping out by a smaller end diameter. Moreover, other techniques like interlocking rips, threaded sleeves, and interlocking steel rings with no complete data were proposed, so the design values where considered as a guiding starting point. Table- II shows a summary for the bar embedded lengths required to provide the minimum nominal tensile capacities of $152.6 \mathrm{kN}, 294.4 \mathrm{kN}$, and $482.3 \mathrm{kN}$ for $18 \mathrm{~mm}$, $25 \mathrm{~mm}$ and $32 \mathrm{~mm}$ diameter bars, respectively. These values were determined based on a nominal ultimate tensile strength of $600 \mathrm{MPa}$. These bar embedded lengths were designed based on the equations available in the literature. 
Table- II Summary of preliminary design results for bar $18 \mathrm{~mm}$, bar $25 \mathrm{~mm}$, and $32 \mathrm{~mm}$ grouted splices

\begin{tabular}{|c|c|c|}
\hline Equation Name & Belal & Eliya and George \\
\hline Bar diameter (mm) & 18 & 18 \\
\hline $\begin{array}{c}\text { Grout compressive } \\
\text { strength (Mpa) }\end{array}$ & 45 & 45 \\
\hline $\begin{array}{c}\text { Required embedded } \\
\text { length (mm) }\end{array}$ & 170 & 300 \\
\hline
\end{tabular}

\section{PREPRATION OF SPECIMENS}

The specimens were prepared in several stages: Stage 1cutting the ASTM pipes to the required lengths as shown in Fig.5. Stage 2 - cutting the steel rings from the smaller ASTM pipes and welding the rings inside pipes as shown in Fig.6. Stage 3-install the bars to be spliced then pour the mortar to grout the sleeves as shown in Fig.7. The 50*50*50 mm grout cubes were prepared to be tested later to find out the actual compressive strength of the grout. Also, steel bar samples were cut to be tested later to find the actual steel yield and ultimate strength.

\section{Fig. 5 Cutting the ASTM pipes}

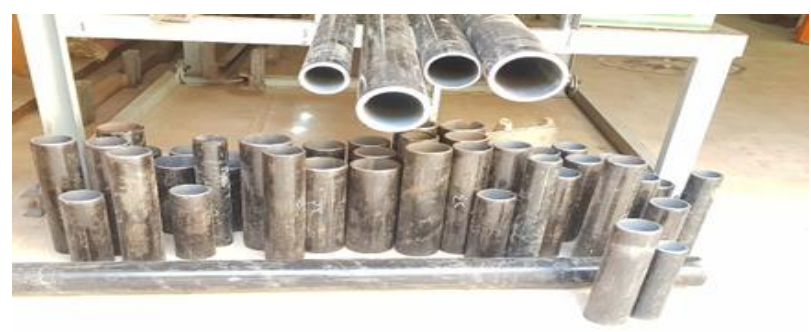

Fig. 6 Cutting the steel rings
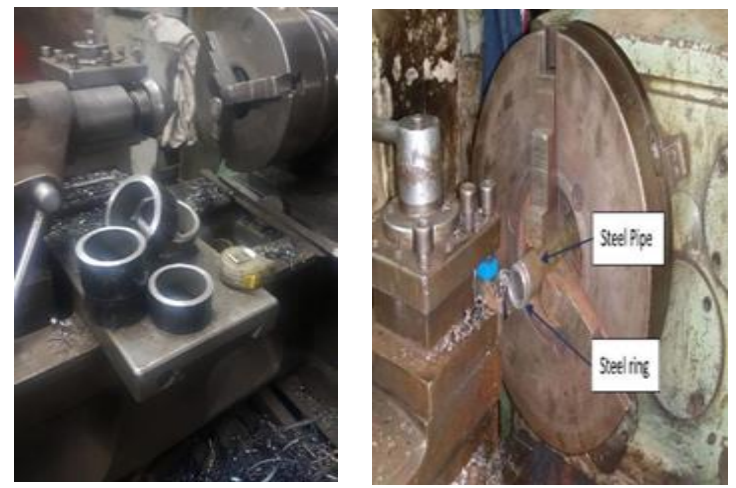

D. TESTING

\section{SPECIMENS}

The specimens were tested to investigate the mechanical behavior of the splices and the effect of the interacting parameters on the bond behavior. First, the grout cubes were tested using universal testing machine to assess the actual grout compressive strength. Second, the steel bars were tested under axial tensile load to get the actual yield and ultimate strength. Third the specimens were tested under axial tensile force by Shimazu universal testing machine as shown in Fig. 8 to determine the max load and the mode of failure.

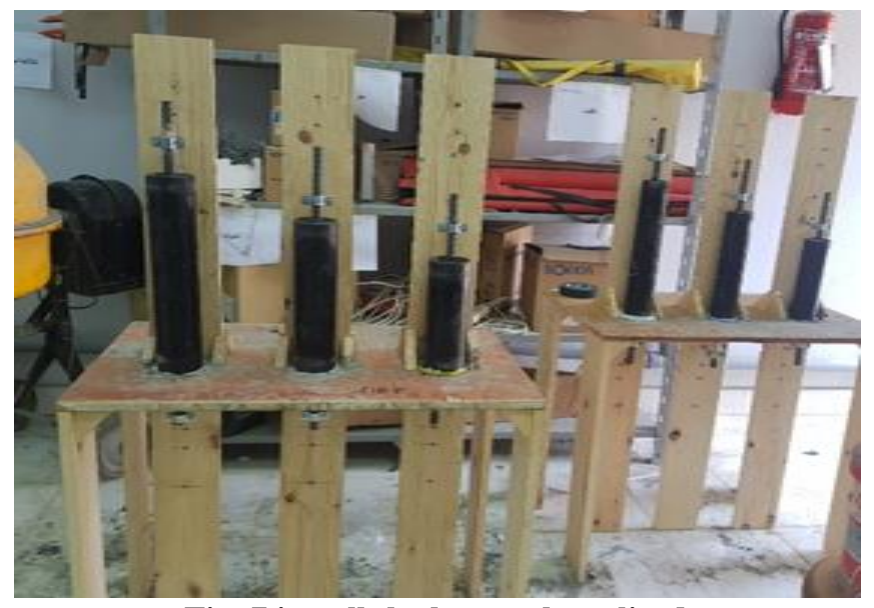

Fig. 7 install the bars to be spliced

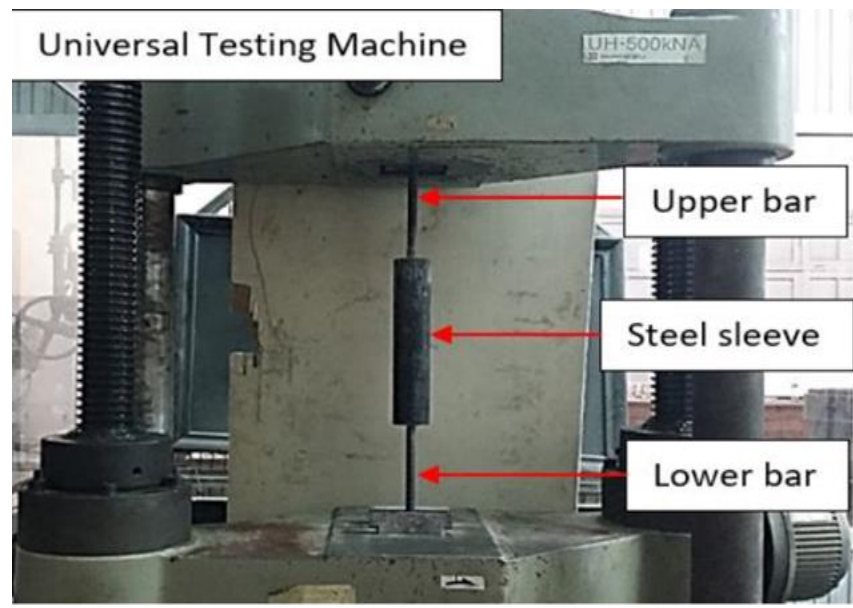

Fig. 8 Tested of grouted splice sleeve specimens under axial tensile load

\section{RESULTS AND DISSCUSION}

\section{A. RESULTS OF TESTED GROUTED SPLICE SLEEVE SPECIMENS}

Table- A2 appendix A shows a summary for the results of all the specimens. The grout compressive strength, the ultimate tensile capacity, the bond strength, and the mode of Failure are recorded. The results show that the proposed grouted splice sleeve specimens provided with welded interlocking steel rings either failed due to bar-to-grout bond Failure or bar fracture. On the other hand, grouted splice sleeve specimens with no or insufficient interlocking between the grout and the sleeve failed by grout-to-sleeve bond Failure. Welding an interlocking steel ring, with a minimum thickness of $7 \mathrm{~mm}$, significantly increases the tensile capacity of the splice. This was achieved by enhancing the confinement stress, the bar-to-grout bond strength, and preventing the grout-to-sleeve bond Failure.

\section{B. ANALYSIS OF EXPERIMENTAL TEST RESULTS}

\section{- MODES OF FAILURE}

Three modes of Failure were detected for the specimens in the test program, namely: bar-to-grout bond failure as shown in Fig. 9, bar fracture as shown in 
Fig. 10, and grout-to-sleeve bond Failure as shown in Fig. 11. Clearly, splice specimens with no sleeves failed when the grout tensile strength was reached.

The bar-to-grout bond failure mode occurs when the bond capacity between the spliced bars and the grout cannot resist the tensile load. This can be attributed to an insufficient bar embedded length whose required value is affected by various parameters. Different values of the tensile capacity of the specimens were reported for bar-grout bond failure mode and they varied due to different configurations of the sleeves affecting the confinement, or different bar embedded lengths, or different grout compressive strengths. This mode occurred in some specimens such as GS2, GS6, GSS13, and GSS19 with tensile capacities of $50 \mathrm{kN}, 99 \mathrm{kN}, 226 \mathrm{kN}$, and $290 \mathrm{kN}$, respectively.

The grout to sleeve bond failure occurred when no or inadequate interlocking mechanisms were introduced to the sleeve wall to prevent the grout from slipping out of the sleeve. When the applied load overcomes the grout-sleeve direct bond resistance, the force is resisted by the grout tensile strength which is a small value with respect to the grout compressive strength. This mode of failure was clearly observed in specimens GSS4, GSS5, GSS6, and GSS8 with tensile capacities of $82.5 \mathrm{kN}, 126.7 \mathrm{kN}, 131 \mathrm{kN}$, and 148.2 $\mathrm{kN}$, respectively. If no or inadequate interlocking mechanism is introduced to the sleeve, the grout will slip out of the sleeve, unless sleeve length is enough to provide the required bond capacity.

Bar fracture occurred when both bar-to-grout bond capacity and grout-to-sleeve bond capacity were adequate and exceeded the bar tensile capacity. In such splices, the ductile failure mode is ensured because of yielding of the spliced bars before the failure of bond. This ductile failure is desirable in designing reinforced concrete structures, so, these connectors, that guarantee the bar fracture mode, are highly recommended. The bar fracture mode was observed in many specimens such as GSS3, GSS12, GSSR3, and GSSR6 with tensile capacities of $151 \mathrm{kN}, 154 \mathrm{kN}, 152.5 \mathrm{kN}$, and $152.2 \mathrm{kN}$, respectively.

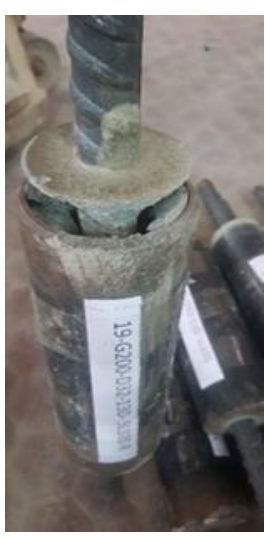

Fig. 9 Bar grout bond Failure

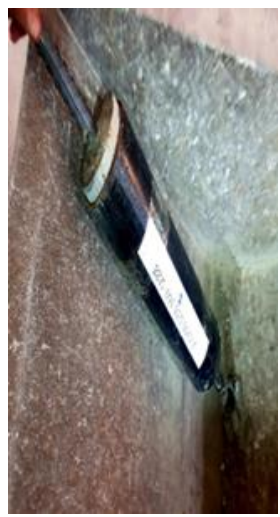

Fig. 10 Grout to sleeve bond failure

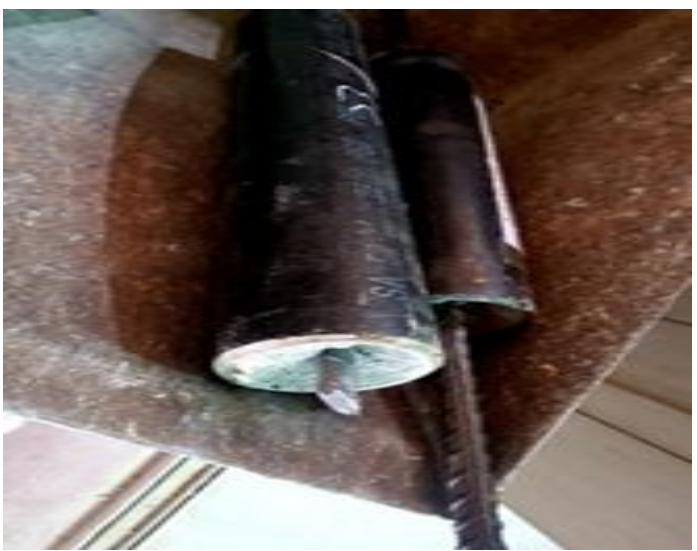

Fig. 11 Bar fracture failure

\section{EFFECT OF STUDIED PARAMTERS}

- GROUT COMPRESSIVE STRENGTH

The comparison shown in Fig.12 reports that increasing the grout compressive strength significantly increases the tensile capacity of the grouted splice sleeve connectors. This can be attributed to the increase of the bond strength between the spliced bars and the grout due to the increase of the grout compressive strength. Moreover, increasing the grout compressive strength leads to an increase in the bearing capacity of the grout at the interlocking steel rings.

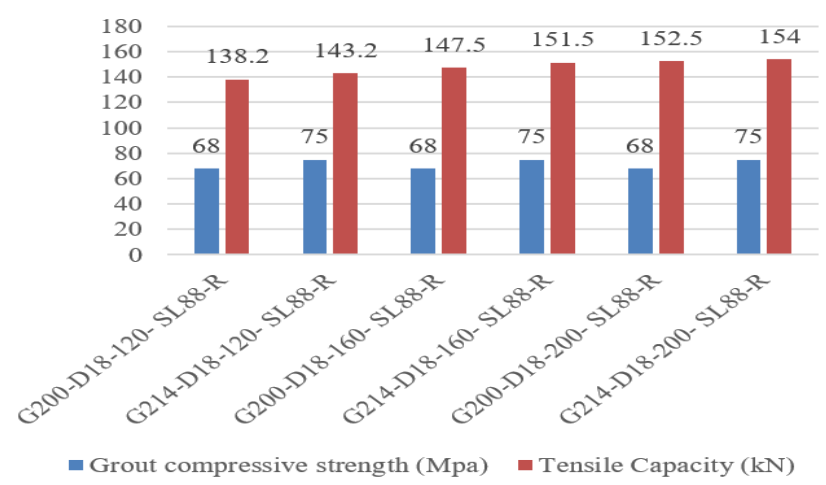

Fig. 12 Grout strength effect on the tensile capacity.

\section{- BAR EMBEDDED LENGTH}

The comparison shown in Fig.13 reports that the tensile capacity increases as the bar embedded length increases. Increasing the bar embedded length means increase of the number of shear keys along the interface of the splicing bars with the surrounding grout and the bar circumferential area enhancing the bond capacity. This results in a significant increase in the tensile capacity.

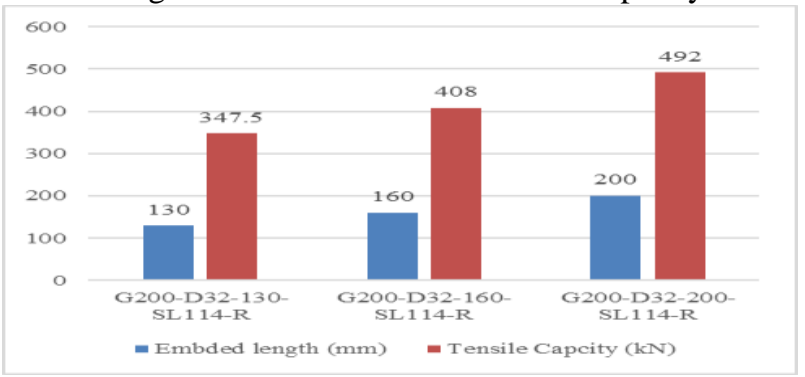

Fig. 13 Embedded length effect on the tensile capacity 


\section{- BAR DIAMETER}

The comparison shown in Fig.14 reports that increasing the bar diameter from $18 \mathrm{~mm}$ to $25 \mathrm{~mm}$ developed a notable increase in the tensile capacity of the grouted splice sleeve connectors. This is due to two reasons: As the bar diameter increases, the embedded circumferential area increases. Also, as the bar diameter increases, the grout volume surrounding the bar decreases, consequently, the bar is more confined. The higher the confining stress on the grout, the larger the tensile capacity value of the grouted splice sleeves.

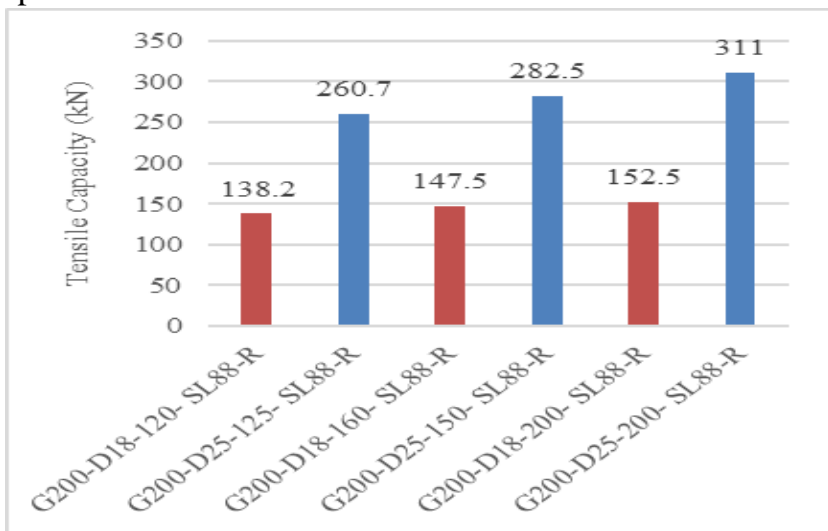

Fig. 14 Bar diameter effect on the tensile capacity.

- SLEEVE DIAMETER EFFECT

Increasing sleeve diameter splicing the same bar diameters means a decrease in the confining stress on the grout surrounding the spliced bars. Consequently, this leads to a decrease in the tensile capacity of the connection. This is attributed to the decrease of the bond strength due to the reduction of the confining stress. Fig. 15 shows the effect of changing sleeve diameter on the tensile capacity.

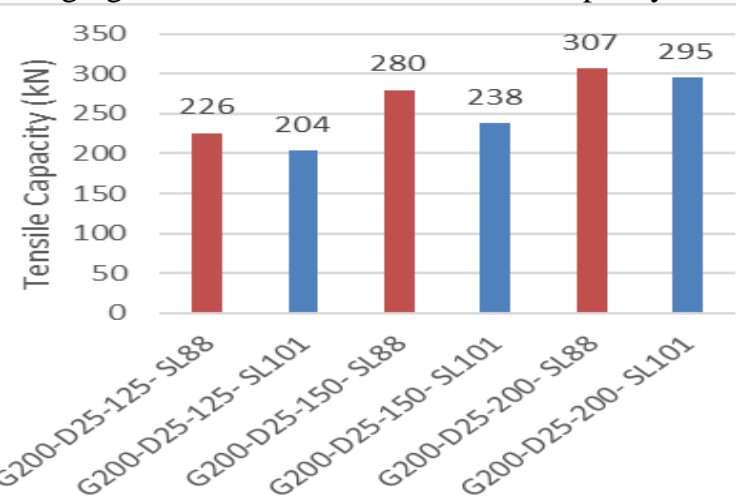

Fig. 15 Sleeve diameter effect on the tensile capacity.

- SLEEVE WALL THICKNESS EFFECT

Increasing sleeve thickness of the same bar diameter and the same sleeve outer diameter increase the tensile strength due to the increase in confining stress on the grout surrounding the spliced bars. This may be attributed to increase of the bond stress due to increase the confining stress. Fig. 16 reports the effect of changing sleeve wall thickness from $5.49 \mathrm{~mm}$ to $7.62 \mathrm{~mm}$ for the same sleeve out diameter $88.9 \mathrm{~mm}$ that is showed increase in tensile strength from $82.5 \mathrm{kN}$ to $136 \mathrm{kN}$.

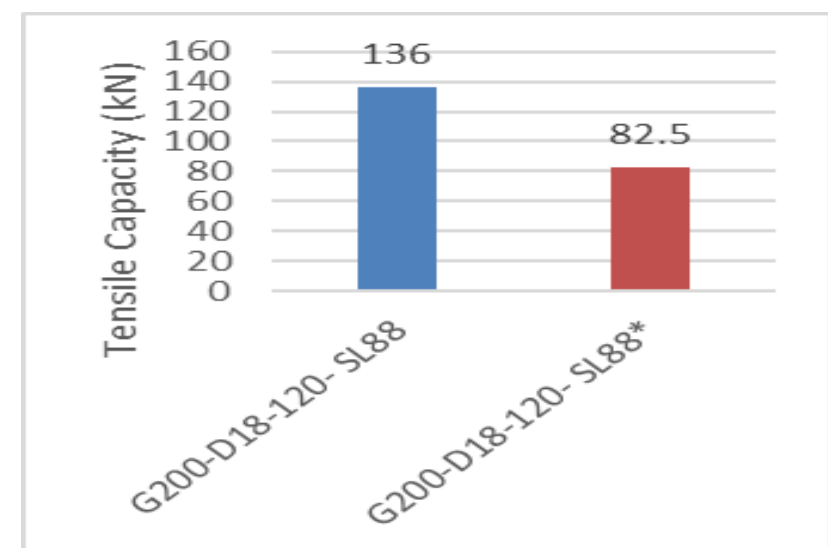

Fig. 16 Wall thickness effect on the tensile capacity.

- SLEEVE CONFIGURATION EFFECT

Introducing interlocking steel rings at both ends of the inner sleeve wall significantly increased the tensile capacity of the grouted bar splice. Constraining the grout inside the sleeve prevents the grout-sleeve bond Failure and increases the confining stress which enhances the bar-grout bond strength as well. Fig. 17 shows the effect of welding ring on the tensile capacity.

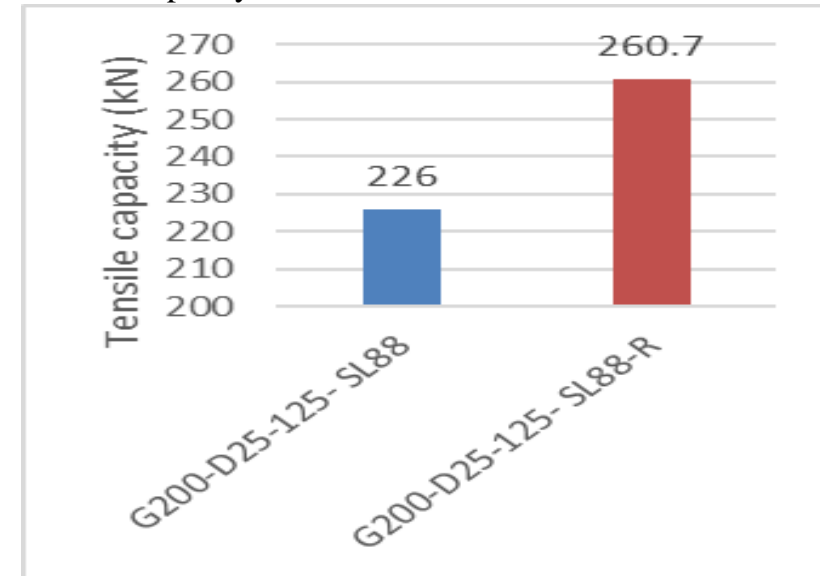

Fig. 17 Welding ring effect on the tensile capacity.

\section{- DETERMINING THE ADEQUACY OF TESTED SPECIMENS ACCORDING TO ACI 318-14 AND ECP 203-2018}

To check the adequacy of the tested specimens, the yield ratio, $R_{\mathrm{y}}$, and the ultimate ratio, $R_{\mathrm{u}}$, were calculated and reported in Table- A2 Appendix A. The yield ratio, $R_{\mathrm{y}}$, can be defined as the ratio of the tensile capacity of the specimen and the yield strength of the bar. The ultimate ratio, $R_{\mathrm{u}}$, can be defined as the ratio of the tensile stress of the specimen and the ultimate strength of the bar. According to ACI 318-14 [1] a mechanical splice type 1 and ECP 203-2018[5], the splice is considered satisfactory when the ultimate tensile capacity of the splice is $125 \%$ times the yield strength of the spliced bars. So, the yield ratio, $R_{\mathrm{y}}$, should be at least 1.25.Meanwhile, in accordance with ACI[1] 318-14, type 2 mechanical splices, which are used in lateral load resisting frames or shear walls, should sustain the tensile strength of the spliced bars. For these purposes, only specimens with ultimate ratio, $R_{\mathrm{u}}$, greater than or equals to 1 shall be adequate for type 2 mechanical splices. 
Clearly, all the bar-fractured specimens are considered satisfactory according to ACI 318-14[1] type 2 where the ultimate ratio, $\mathrm{Ru}$, values ranged from 1 to 1.05 provisions for type 2 mechanical splices. Also, the specimens with Ry ranging from 1.25 to 1.58 are adequate with respect to the ACI 318-14[1] type 1 and ECP 203-2018[5] provisions for mechanical splices. This shows that for $18 \mathrm{~mm}$ diameter reinforcing steel bars, grout 214, and a SL73 without interlocking steel rings, an embedment length of $120 \mathrm{~mm}$ is adequate to satisfy type 1 , while an embedment length of 200 $\mathrm{mm}$ is required to satisfy type 2. Similarly, for $18 \mathrm{~mm}$ diameter reinforcing steel bars, grout 214, and a SL73 with interlocking steel rings and an embedment length of $120 \mathrm{~mm}$ is adequate to satisfy type 1 mechanical splices, while an embedment length of $160 \mathrm{~mm}$ is required to satisfy type 2 mechanical splices. Comparing these results to the initial design procedures performed according to the reported design equations available in literature, it can be seen that the equation developed by Belal reported that the embedded length for type 1 equal $100 \mathrm{~mm}$ and equal $120 \mathrm{~mm}$ for type 2 which were less than the actual values, and the equations derived by Eliya and George reported that the embedded length for type 1 is $160 \mathrm{~mm}$ and is $193 \mathrm{~mm}$ for type 2 which were too conservative. The equations in the literature didn't cover the effect of all the parameters affecting the design of the grouted splice sleeves.

\section{PROPOSED COMPREHENSIVE DESIGN PROCEDURES}

Based on the results of the experimental program, the following design equations present a simple formula using a linear regression method to evaluate the initial grout bond strength, $t_{b i}$, as a function of grout compressive strength, fg, (Eq. 13) GS specimens. The bar-to-grout bond strength, Ub, will be calculated as a function of the grout compressive strength, fg, the sleeve inside diameter, ds in, the sleeve wall thickness, ts, the bar diameter, $\mathrm{db}$, and the bar embedded length, Lb, (Eq. 14 ) was derived for GSS and (Eq. 15) for GSSR specimens. The equations can determine the required embedded length to satisfy either type 1 or type 2 connection using chosen sleeve that, fits the spliced bars using available standard steel pipes and commercially available grouts to accommodate precast or cast-in-situ concrete construction.

Where:

$$
\begin{aligned}
& \text { fg = grout compressive strength }(\mathrm{MPa}) \\
& \text { tbi = initial bond strength }(\mathrm{MPa}) \\
& \mathrm{Ub}=\text { bar-to-grout bond strength }(\mathrm{MPa}) \\
& \mathrm{ds} \text { in = sleeve inner diameter }(\mathrm{mm}) \\
& \text { ts = sleeve wall thickness }(\mathrm{mm}) \\
& \mathrm{db}=\text { spliced bar diameter }(\mathrm{mm}) \\
& \mathrm{lb}=\text { spliced bar embedded length }(\mathrm{mm})
\end{aligned}
$$

\section{- VERIFICATION OF PROPOSED EQUATIONS}

For verification purposes, the results of the tested specimens are compared to the predicted values of the proposed equations throughout substituting the values of the studied parameters of the tested specimens into these equations. The predicted values of bar-to-grout bond and grout-to- sleeve bond capacities are compared to the test values. It was found that the proposed equations give good reliable values for initial grout bond strength, tbi, as shown in Table- A3 Appendix A and bar-to-grout bond strength of the grouted splices, Ub, as shown in Table- A4 Appendix A for GSS specimens and Table- A5 Appendix A for GSSR specimens. The strength ratio, $R$, can be calculated bydividing the bond strength of the tested GS specimens by the bond strength calculated according to Eq. (13) for GS specimens as shown in Table- A3 Appendix A. The strength ratio, $R$, for GS specimens ranged from 0.87 to1.12. These values indicate that the proposed equations give reliable values with an error varying between $+12 \%$ and $-13 \%$.

Based on the verification of the proposed equation and the strength ratio, $R$, a reduction factor namely initial bond strength reduction factor, $\beta_{\mathrm{i}}$, was set to be 0.88 as shown in Eq. (16). The application of such a factor means that the values of the initial bond strength determined by the proposed design Eq. (16) are always less than those acquired experimentally.

Where:

$$
\begin{aligned}
\mathrm{t}_{\mathrm{bc}} & =\text { corrected initial bond strength }(\mathrm{MPa}) \\
\mathrm{tbi} & =0.75 \mathrm{Jfg}
\end{aligned}
$$

$\frac{\mathrm{db}}{V_{\mathrm{fg}}}=0.0064 * \mathrm{ds}$ in $+0.1871 * \mathrm{ts}+0.0648 \mathrm{db} \cdot 0.006 * \mathrm{Lb}$

$$
\frac{v_{b}}{\sqrt{f g}}=1.747 \cdot 2.45 * 10^{-3} * d s i n+0.05976 * t s+8.475 * 10^{-2} * d b \cdot 8.84 * 10^{-3} * \mathrm{Lb}(15)
$$

$\beta_{\mathrm{i}}=$ initial bond strength reduction factor $=0.88$

The

$$
\text { tbc }=\beta_{\mathrm{i}} * 0.75 \sqrt{\mathrm{fg}}
$$

strength ratio, $R$, was calculated by dividing the bond strength of the tested GSS specimens by the bond strength calculated according to Eq. (14) for GSS specimens as shown in Table- A4 Appendix $\mathrm{A}$, and it was ranging from 0.83 to1.16. These values indicate that the proposed equations give reliable values with an error varying between $+16 \%$ and $-17 \%$. To ensure that predicted value doesn't exceed the experimental value a reduction factor, namely, total bond reduction factor for GSS specimens, $\beta_{\mathrm{s}}$, was set to be 0.84 as shown in Eq. 17 .

Where:
$\mathrm{U}_{\mathrm{bd}}=$ corrected total bond strength $(\mathrm{MPa})$
$\beta_{\mathrm{s}}=$ bond strength reduction factor for GSS specimen =
0.84

The strength ratio, $R$, was calculated by dividing the bond strength $\quad \mathbf{U}_{\mathbf{b d}}=\boldsymbol{\beta}_{\mathrm{s}} * \mathbf{U} \mathbf{b} \quad$ of the tested GSSR specimens by the bond strength calculated according to Eq. (15) for GSSR specimens as shown in Table- A5 Appendix A , and it was ranged from 0.87 to1.13. 
These values indicate that the proposed equations give reliable values with an error varying between $+13 \%$ and -13 $\%$. To ensure that predicted value doesn't exceed the experimental value a reduction factor namely total bond reduction factor for GSSR specimens, $\beta_{\mathrm{r}}$, was set to be 0.87 as shown in Eq. 18.

(18)

Where:

$\mathrm{U}_{\mathrm{bd}}=$ corrected total bond strength (MPa)

$\beta_{\mathrm{r}}=$ bond strength reduction factor for GSSR specimens = 0.87

\section{CONCLUSIONS}

The results of the experimental work of this study showed that reinforcing steel bars with $18 \mathrm{~mm}, 25 \mathrm{~mm}$, and $32 \mathrm{~mm}$ diameter can be adequately spliced using grouted splice sleeves fabricated from commercially available standard steel pipes and cementitious high strength non-shrink grouts. The studied parameters exhibited a great influence on the mechanical behavior of the grouted splices, especially, the sleeve wall thickness and the bar embedded length. Moreover, the confinement stress added by the sleeve to grouted splice sleeve connectors significantly enhanced the bar-to-grout bond strength, consequently, enhanced the whole capacity of the grouted splices. The results of the research used to derive design equations for grouted sleeve splices and get the required embedded length to satisfy the code requirements using the chosen sleeve Conclusions can be summarized as follows:

1. 36 grouted splice sleeve specimens are considered satisfactory in accordance with ACI 318-14[1] for type 1 mechanical splice, and ECP 203-2018[5] for mechanical splices, moreover 10 grouted splice sleeve specimens are considered satisfactory in accordance with ACI 318-14[1] for type 2 mechanical splice. As a result, these splices can be adequately used in field construction.

2. Increasing grout compressive strength increase the initial bond strength and the total bond strength.

3. The total bond strength increasing with the increasing of embedded length, bar diameter, and wall thickness.

4. Increasing the sleeve inside diameter decrease the total bond strength.

5. Introducing interlocking steel rings with a minimum thickness of $7 \mathrm{~mm}$ to the both ends of the inner sleeve wall was adequate and the tensile strength of the spliced bars was reached. The steel rings prevent the grout to sleeve bond failure.

6 . The results of the tested specimens were compared to the predicted values of the bar-to- grout bond

$\mathbf{U}_{\mathbf{b d}}=\boldsymbol{\beta}_{\mathbf{r}} * \mathbf{U} \mathbf{b}$ strengths calculated from the proposed equations. It was found that the proposed equations give good reliable values for the bar-to-grout bond strength.

7. Based on the proposed equations validated experimentally, the authors recommend the splice sleeve as mention in Table- III for grout sleeve splice specimens and as mention in Table- IV for grout sleeve splice with $7 \mathrm{~mm}$ interloacking ring specimens to meet the ECP 203-2018[5] and ACI 318- 14 [1] requirements for mechanical splices.it should be noted that additional testing is recommended to confirm the performance of splice sleeves for bar size other than $18 \mathrm{~mm}, 25 \mathrm{~mm}$, and $32 \mathrm{~mm}$.

Table- III: Recommended sleeve dimension for GSS specimens.

\begin{tabular}{|c|c|c|c|c|c|c|c|}
\hline \multirow{3}{*}{$\phi$} & \multicolumn{5}{|c|}{ Sleeve } & \multirow{2}{*}{\multicolumn{2}{|c|}{$\mathrm{Lb}$}} \\
\hline & \multirow[b]{2}{*}{ ds out } & \multirow[b]{2}{*}{ ds in } & \multirow[b]{2}{*}{ ts } & \multicolumn{2}{|c|}{ Ls } & & \\
\hline & & & & Type 1 & Type 2 & $\begin{array}{c}\text { Type } \\
1 \\
\end{array}$ & $\begin{array}{c}\text { Type } \\
2\end{array}$ \\
\hline 16 & 60.33 & 51.59 & 8.74 & 220 & 280 & 100 & 130 \\
\hline 18 & 60.33 & 51.59 & 8.74 & 240 & 300 & 110 & 140 \\
\hline 20 & 73.03 & 66.02 & 7.01 & 300 & 370 & 140 & 175 \\
\hline 22 & 73.03 & 66.02 & 7.01 & 310 & 400 & 145 & 190 \\
\hline 25 & 73.03 & 66.02 & 7.01 & 330 & 430 & 155 & 205 \\
\hline 28 & 73.03 & 66.02 & 7.01 & 350 & 450 & 165 & 215 \\
\hline 32 & 73.03 & 66.02 & 7.01 & 370 & 480 & 175 & 230 \\
\hline 40 & 73.03 & 66.02 & 7.01 & 400 & 500 & 190 & 240 \\
\hline
\end{tabular}

Table- IV: Recommended sleeve dimension for GSSR specimens.

\begin{tabular}{|c|c|c|c|c|c|c|c|}
\hline \multirow{2}{*}{$\Phi$} & \multicolumn{5}{|c|}{ Sleeve } & \multicolumn{2}{c|}{ Lb } \\
\cline { 2 - 7 } & \multirow{2}{*}{ ds out } & \multirow{2}{*}{ ds in } & ts & \multicolumn{2}{|c|}{ Ls } & \multicolumn{2}{c|}{} \\
\cline { 5 - 8 } & & & & Type 1 & Type 2 & $\begin{array}{c}\text { Type } \\
1\end{array}$ & $\begin{array}{c}\text { Type } \\
2\end{array}$ \\
\hline 16 & 60.33 & 51.59 & 8.74 & 190 & 230 & 85 & 105 \\
\hline 18 & 60.33 & 51.59 & 8.74 & 210 & 250 & 95 & 115 \\
\hline 20 & 73.03 & 66.02 & 7.01 & 230 & 290 & 105 & 135 \\
\hline 22 & 73.03 & 66.02 & 7.01 & 240 & 300 & 110 & 140 \\
\hline 25 & 73.03 & 66.02 & 7.01 & 260 & 320 & 120 & 150 \\
\hline 28 & 73.03 & 66.02 & 7.01 & 270 & 340 & 125 & 160 \\
\hline 32 & 73.03 & 66.02 & 7.01 & 280 & 350 & 130 & 165 \\
\hline 40 & 73.03 & 66.02 & 7.01 & 300 & 380 & 140 & 180 \\
\hline \multicolumn{7}{|c|}{ Grout Compressive strength = 80 MPa } \\
\hline
\end{tabular}

\section{REFERENCES}

1. ACI 318-14 (2014), Building Code Requirements for Structural Concrete and Commentary, Building Code Requirements for Structural Concrete (ACI 318-14) An ACI Standard Commentary on Building Code Requirements for Structural Concrete (ACI 318R-14) An ACI Report, American Concrete Institute; Michigan, United States.

2. ASTM A106 Grade B (2015), ASTM A106 / A106M - 15 Standard Specification for Seamless Carbon Steel Pipe for High-Temperature Service; ASTM INTERNATIONAL. https://www.astm.org/Standards/A106.htm

3. Belal Ali "Experimental study of the mechanical behavior of grouted spliced sleeve connections for precast concrete construction under axial load"2016.

4. Darwin D, Zuo J, Tholen ML, Idun EK. Development length criteria for conventional and high relative rib area reinforcing bars. ACI Struct J 1996;93(3):1-13.

5. ECP (2018), Egyptian Code of Practice: ECP 203-2007, Egyptian Code for Design and Construction of Concrete Structures (ECP 203-2018), Housing and Building National Research Center; Giza, Egypt. 
6. Einea, A., Yamane, T. and Tadros, M.K. (1995), "Grout-Filled Pipe Splices for Precast Concrete Construction”, PCI Journal, 40(1), 82-93.

7. Eliya Henin, George Morcous "Non-proprietary bar splice sleeve for precast concrete construction", Engineering Structures 83 (2015) 154-162

8. Ling, J.H., Ahmad, A.B., Ibrahim, I.S. and Abdul Hamid, Z. (2016), "Tensile capacity of grouted splice sleeves", Engineering Structures, 111, 285-296.

9. SIKAgrout ${ }^{\circ} \quad 200 \quad$ (2015), SIKAgrout ${ }^{\circ} \quad-200$ High strength, Non-shrink, None oxidized Cementitious Grout; Sika Egypt for Construction Chemicals, El Abour City, Egypt. https://egy.sika.com/dms/getdocument.get/69829980-8be7-3fc6-b4c8c2cc41cc41a6/Sikagrout ${ }^{\circledR}-200$

10. SIKAgrout ${ }^{\circledR} \quad 214 \quad$ (2015), SIKAgrout ${ }^{\circledR} \quad-214$ High strength, Non-shrink, None oxidized Cementitious Grout; Sika Egypt for Construction Chemicals, El Abour City, Egypt. https://egy.sika.com/dms/getdocument.get/69829980-8be7-3fc6-b4c8c2cc41cc41a6/Sikagrout ${ }^{\circledR}$-214

\section{AUTHORS PROFILE}

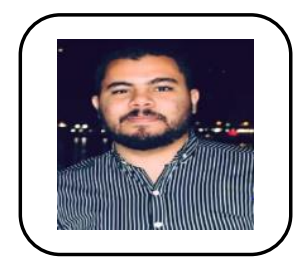

Abdallh M.Soliman - PhD student at structural department faculty of engineering Cairo university.

He has master's in science in concrete to his credit. His area of research is precast concrete specially the splice between concrete and steel reinforcement. He has published paper in the field of concrete - concrete composite section

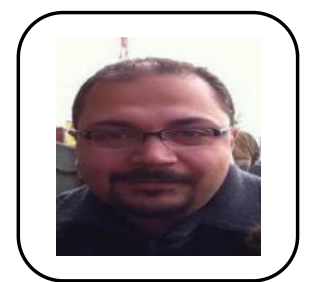

Hatem H. Ibrahim- he is an assistant professor in department of structural at faculty of engineering Cairo university.He has master's in science from Cairo university and $\mathrm{PhD}$ degree from university of Alberta Canada . He has published many papers in the field of properties and strength of materials.

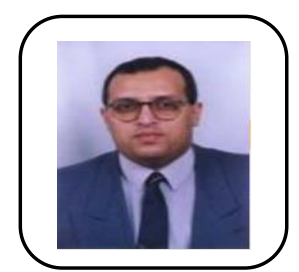

Hossma A. Hodhod - he is a professor in department structural at faculty of engineering Cairo university.He has master's in science from Cairo university and $\mathrm{PhD}$ degree from university of Tokyo. He has published many papers in the field of properties and strength of materials. 